\title{
Adult Attention Deficit Hyperactivity Disorder and Suicide Attempters: A Case Control Study From Iran, West Asia
}

\author{
Masoud Mozhdehi Fard, ${ }^{1}$ Mitra Hakim Shooshtari, ${ }^{1}$ Mohammad Reza Najarzadegan, ${ }^{1}$ Terme \\ Khosravi, ${ }^{1}$ Reza Bidaki, ${ }^{2,3,}{ }^{*}$ Maziar Moradi, ${ }^{1}$ Maryam Pourshams, ${ }^{1}$ Hamide Mohammadi Farsani, ${ }^{1}$ Zahra \\ Ghiasi, ${ }^{1}$ and Seyed Ali Mostafavi ${ }^{4}$ \\ ${ }^{1}$ Department of Psychiatry, Tehran Institute of Psychiatry, Faculty of Behavioral Science and Mental Health, Iran University of Medical Sciences, Tehran, IR Iran \\ ${ }^{2}$ Research Center of Addiction and Behavioral Sciences, Shahid Sadoughi University of Medical Sciences, Yazd, IR Iran \\ ${ }^{3}$ Diabetes Research Center, Shahid Sadoughi Unversity of Medical Sciences and Health Services, Yazd , IR Iran \\ ${ }^{4}$ Psychiatry Research Center, Roozbeh Hospital, Tehran University of Medical Sciences, Tehran, IR Iran \\ "Corresponding author: Reza Bidaki, Research Center of Addiction and Behavioral Sciences, Shahid Sadoughi University of Medical Sciences, Yazd, IR Iran. Tel/Fax: \\ +98-3532633555, E-mail: Reza_Bidaki@yahoo.com
}

Received 2015 May 05; Revised 2016 February 15; Accepted 2016 March 14.

\begin{abstract}
Background: Childhood attention deficit hyperactivity disorder (ADHD) persists into adulthood in up to two thirds of affected patients. Usually, ADHD has co-morbidities with several psychiatric disorders, and its symptoms occur more frequently in suicide attempters and may thus be a reason for the completed act of suicide.

Objectives: The aim of the current study was to compare adult suicide attempters affected by ADHD with other suicide attempters without a history of suicide attempts that referred to the outpatient clinic.

Patients and Methods: This case control study was conducted at Loghman-Hakim hospital, Tehran, during a one year period. A total of 394 hospitalized patients in the poison control center that had attempted suicide were recruited. In the control group, 394 individuals without a history of suicide attempts were recruited from referrals to the outpatient clinic of Loghman-Hakim hospital, which provides services for almost all medical specialties. We used Conners' adult ADHD rating scale, including the screening version form and subscale (CAARS-S: SV), the Wender Utah rating scale (WURS), and clinical interviews for diagnosis of ADHD. The hypothesis was tested using an independent samples t-test and ANOVA.

Results: The results of our study showed that a history of psychiatric disorders and a family history of ADHD and suicide were significantly higher $(\mathrm{P}>0.01)$ in the case group than the control group. In addition, both children and adult ADHD among suicide attempters were significantly higher $(\mathrm{P}>0.01)$ than the corresponding rates in the control group.

Conclusions: ADHD is a common co-morbidity among suicide attempters. Hence, early diagnosis and treatment with consideration of ADHD may reduce suicide attempt risk.
\end{abstract}

Keywords: Attention Deficit Disorder with Hyperactivity, Suicide, Iran, Treatment, Prevention

\section{Background}

Attention deficit / hyperactivity disorder (ADHD) is a common condition in children and adolescents. ADHD persists into adulthood in up to two thirds of affected patients (1), and the worldwide pooled prevalence rate of adult ADHD is $2.5 \%(2,3)$. Adults with ADHD suffer from attention and concentration impairment, restlessness, irritability, and impulsive behaviors (4). ADHD induces a significant risk for functional impairments over the course of an individual's life span. Attention problems can lead to impaired academic achievement and FTT (5, 6), along with disturbed social and psychological functioning in adulthood (7). Adults with ADHD exhibit lower selfesteem, poorer lifetime academic achievements, less successful work histories, and greater marital problems (8).
Furthermore, ADHD is associated with several psychiatric disorders (co-morbidities) such as antisocial personality disorder, substance misuse, and affective disorders (9). Finally, it is especially worth noting that ADHD symptoms occur more frequently among suicide attempters and may be a reason for the completed suicide attempt (10).

Suicide is recognized as a major public health problem throughout the world. In Iran, a total number of 41,109 suicide attempts and 1,338 cases of completed suicide were reported from March 2009 to March 2010, which were equal to 65.76 and 2.14 cases per 100,000 people, respectively (11). There is an increased risk of suicide attempts among patients with borderline personality disorder (12)and bipolar disorder (13). Both of these conditions have symptomatic overlaps with ADHD, so some degree of suicidal tendencies 
may also be shared. This raises the question of whether there is a direct association between ADHD and suicide.

A study on Korean female adolescents has shown that all subtypes of ADHD may lead to depression, which itself can then lead to suicidal ideation. Therefore, the relationship between ADHD and suicide attempts can be considered to be at least partially mediated by depression (14).

In a review article, the results of long-term follow-up studies on ADHD have been evaluated. It appears that ADHD increases the risk of suicide attempts in males via increasing the severity of co-morbid conditions, and when ADHD is one of these co-morbidities along with other psychiatric conditions, it could be considered as a risk factor (15). Ultimately, what was shown is that individuals with ADHD have more suicidal ideas and make more suicide attempts (16).

In 2011, Agosti and colleagues found that of the 365 adults studied with ADHD, $16 \%$ attempted suicide. They showed that ADHD increases the risk of suicide attempts 1.5 fold, and having one or more co-morbid disorders was associated with a four to twelvefold elevated risk. Based on this study, ADHD alone was not a strong predictor of suicide attempts (17).

\section{Objectives}

The aim of the current study was to compare individuals with adult ADHD disorder to those without a history of suicide that referred to an outpatient clinic. In this study, we examined the possible association between adult ADHD and suicide attempts in Iranian adults.

\section{Patients and Methods}

\subsection{Subjects}

This case-control study was conducted at LoghmanHakim hospital, Tehran, during a one year period (August 2012 to September 2013). Loghman-Hakim hospital is a unique poison treatment referral center in Tehran that admits patients from all cities in Tehran province. Informed consent was obtained from all participants. The age range was 18 to 60 years.

\subsubsection{Case Group}

394 hospitalized patients in the poison control center who had attempted suicide were recruited. The exclusion criteria were illiteracy, poor reading ability, instability in physiological condition, and any disturbance in orientation or consciousness that could impede cooperation and the ability to provide accurate responses to the questionnaires.

\subsubsection{Control Group}

In the control group, 394 individuals without a history of suicide attempts were recruited from referrals to the outpatient clinic of Loghman-Hakim hospital, which provides services for almost all medical specialties. The control group was matched based on age groups and, gender.

\subsection{Research Instruments}

3.2.1. Conners' Adult ADHD Rating Scale - Self-Report, Including the Screening Version Form and Subscale (CAARS-S: SV)

To date, the Conners' adult ADHD rating scale (CAARS) is frequently used in the assessment of adult ADHD (18). It measures a cross-section of ADHD-related symptoms and behaviors in adults. We used the self-report screening version of the CAARS (CAARS-S:SV) containing the DSM-IV ADHD symptom measures and the ADHD index, both of which are useful when a quick screen is needed for DSM-IV ADHD symptoms (including all three DSM-IV subtypes of ADHD) (19). The CAARS-S: SV consists of 30 items which are rated on a Likert scale. On this scale, symptoms are rated as exhibited by the subject either never or rarely (score $=$ 0 ), sometimes (score $=1$ ), often ( score $=2$ ), or usually (score =3). The CAARS has demonstrated strong internal consistency and inter-rater reliability, as well as sensitivity to treatment outcomes (20). For instance, Davari-Ashtiani et al. evaluated the validity and reliability of the Persian version of CAARS-S: SV. The intraclass correlation coefficient and Cronbach's alpha were higher than 0.7 and 0.8 for all domains, respectively. The results showed the CAARS-S can stand alone as a screening instrument in the epidemiological study of adult ADHD in Iran (21).

\subsubsection{Wender Utah Rating Scale (WURS)}

The Wender Utah rating scale (WURS) was developed to evaluate the childhood symptoms of ADHD retrospectively as an aid for the diagnosis of ADHD in adults (22). It is based upon the Utah criteria which were developed to diagnose ADHD in adults. First, a 24 item five-point Likert type self-assessment scale with questions about ADHD symptoms in childhood was developed. The purpose of the WURS is to quantify retrospective self-reports of symptoms including childhood hyperactivity, in attention, and impulsivity. The original study correctly identified $86 \%$ of the patients as having ADHD, 99\% as normal subjects, and $81 \%$ as depressed patients. Internal consistency and testretest reliability after one month of WURS were reported to be high among university students in America in one study (23). Additionally, Sarrami-Foroushani obtained the co-efficients of reliability for the scale (0.95) (24). In another study, the reliability coefficient of the inventory with a sample size of 361 subjects was 0.90 (25). 


\subsection{Clinical Interviews}

Individuals selected based on the interpretation of questionnaires that met the criteria for ADHD both in childhood and adulthood were subjected to clinical interviews to assess differential diagnoses such as bipolar mood disorders, depressive disorders, anxiety disorders, borderline personality disorder, and other disorders or conditions that share some of the same symptoms with ADHD in order to validate adult ADHD diagnosis and possible comorbidities. Non-structured interviews were conducted by three experienced psychiatrists.

\subsection{Statistical Analysis}

Statistical analysis was performed using SPSS version 16. The socio-demographic correlates were estimated through logistic regression analysis. The hypothesis about the equivalent rates of ADHD among suicide attempters and the control group was tested by using an independent samples t-test. Additionally one way analyses of variance (ANOVA) with a 95\% confidence interval (CI) and a significance level for a two tailed $P$ value $>0.05$.

\section{Results}

The mean age of the participants was $23.7 \pm 9.0$ in the case group and $26.4 \pm 7.1 \mathrm{in}$ the control group $(\mathrm{t}=1.510$, $\mathrm{df}$ $=798, \mathrm{P}=0.131)$. The average number of years of education for members of the case group was $11.5 \pm 3.3$ and for the control group was $11.6 \pm 3.5(\mathrm{t}=0.289, \mathrm{df}=856, \mathrm{P}=0.773)$. Demographic characteristics are summarized in Table 1.

\section{Discussion}

Our study showed that adult ADHD among suicide attempters was significantly higher than the corresponding rates among those who did not have a history of suicide attempts. In considering the odds ratio, the suicide risk of individuals who had ADHD was 2.4 times higher than that of all others. This is supported by previous studies and the odds ratios obtained by them. The highest number of the odds ratio was obtained in the study of LAM (26), which was 3.7, and the lowest quantity of the odds ratio was 3.1 in the study of Kelly (27). However, the question of whether ADHD directly caused the suicide attempt or its co-morbidity should be answered.

In this study, the highest co-morbidity with ADHD was major depressive disorder (MDD). Having MDD as an intermediary between ADHD and suicide was also determined in the study of James and colleagues (28). In their study, in addition to depression, conduct disorder is also mentioned; however, our study did not assess the co-morbidity

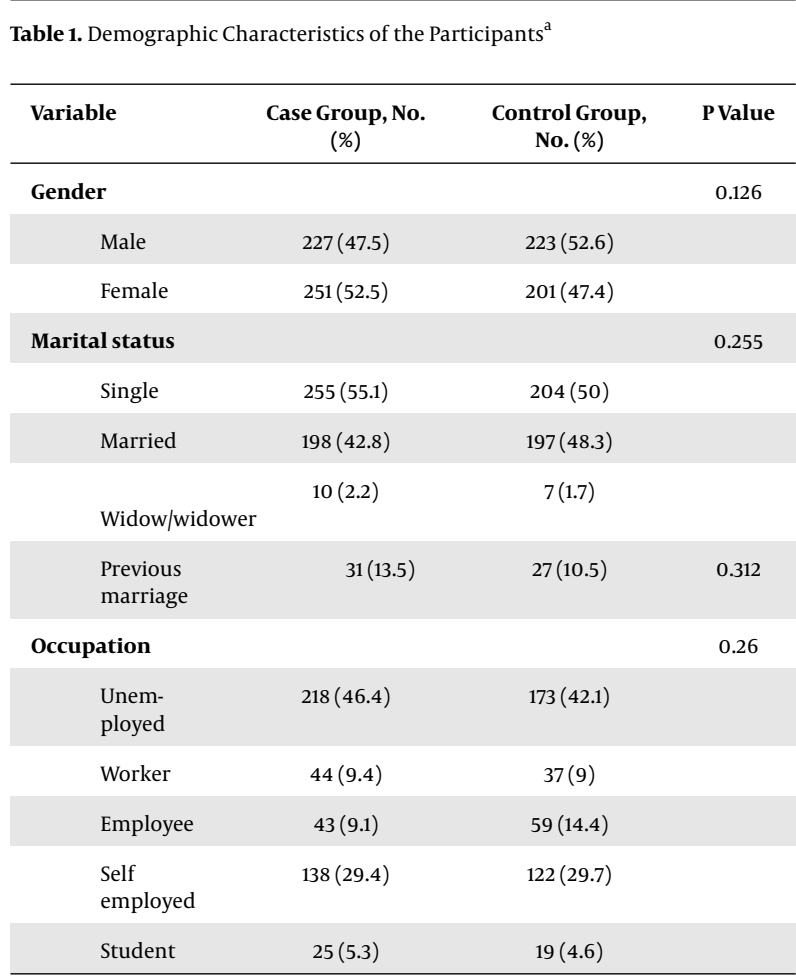

${ }^{\mathrm{a}}$ The history of psychiatric disorder and ADHD in childhood as self-reported weren't significant. Familial history for suicide and ADHD weren't significant, too.

of these disorders because the age of the subjects was over 18 years.

These co-morbid diagnoses were also confirmed in the study of Cho et al. (29). In several long-term follow-up studies, an increase in the co-morbidity of depression and ADHD has been seen in children that reaches about 29\% at younger ages to $45 \%$ at the age of 15 (30). Among other comorbidities of ADHD, the results of our study revealed that bipolar disorder (BID) was significant, which was placed after MDD in the rankings (at 6.15\%). The collection of impulsivity, instability, irritability, and intolerance of failure manifest symptoms similar to ADHD, and the incidence of suicide attempt among patients with these disorders is considerable, such that $25-50 \%$ of individuals with bipolar disorder will have attempted suicide at least once in the course of their lives (31).

It seems that ADHD alone does not cause suicide, and other comorbid conditions play a major role. This finding has been reported in previous studies. For instance, Agosti et al. determined an odds ratio equal to 1.5 in their study when controlling for other co-morbidities. The risk of a suicide attempt was four times higher than in patients with concurrency of other disorders. If two or more of the other disorders were present, the increased risk of suicide was re- 
Table 2. Past Psychiatric History and Familial History of the Participants ${ }^{\mathrm{a}}$

\begin{tabular}{|c|c|c|c|}
\hline Variable & Case Group, No. (\%) & Control Group, No. (\%) & P Value \\
\hline History of psychiatric disorder (self-reported) & $174(37.9)$ & $63(15.3)$ & $<0.01$ \\
\hline History of ADHD (self-reported) & $26(6.2)$ & 0 & $<0.01$ \\
\hline Familial history of ADHD (self-reported) & $60(14.8)$ & $18(6.6)$ & $<0.01$ \\
\hline Familial history for suicide & $91(20.8)$ & $22(7.8)$ & $<0.01$ \\
\hline
\end{tabular}

${ }^{\mathrm{a}}$ The most cause of suicide attempt was a impulsive behavior and conflict with others was the least. The conflict with parents and love failure were other common causes.

Table 3. Suicide Attempt Aharacteristics

\begin{tabular}{|lc}
\hline Variable & Percent \\
\hline Cause of suicide attempt & 21.8 \\
\hline Impulsive & 18.2 \\
\hline Love failure & 16.1 \\
\hline Conflict with parents & 7.4 \\
\hline Economic problems & 4.8 \\
\hline Intimidated by others & 2.5 \\
\hline Conflict with friends & 29.2 \\
\hline Other reasons & \\
\hline Informed persons before suicide attempt & 40.3 \\
\hline Friends & 25.4 \\
\hline Relatives & 12.7 \\
\hline Partner & 11.9 \\
\hline Parents & 79 \\
\hline Others & 36.6 \\
\hline Feeling alive after suicide & 22.5 \\
\hline Good & 40.9 \\
\hline Bad & \\
\hline Apathetic & \\
\hline
\end{tabular}

ported to 12 times higher (32).

It is not clear whether similar mechanisms of the neuronal genes between ADHD and its co-morbidities exist, and it is also not clear whether ADHD first occurs in childhood and continues in adulthood or whether ADHD is concurrently diagnosed with other co-morbidities. However, previous studies have shown that treatment with stimulants in childhood and adolescence increases social and psychological functioning in adulthood (33). The prevalence of the proportion of adult ADHD to childhood ADHD cases in the case group was 0.51 and in the control group was 0.37 . This could be due to the lower co-morbidity and higher recovery rate in the control group, and it may also be because these people may have received more treat- ment for ADHD in childhood. However, both hypotheses could be true, and our study was not able to determine which factor is more effective. Still, it can generally be assumed that ADHD treatment in children will be accompanied by a reduction in the rate of suicide attempts in adulthood.

It is important to note that the sample of this study may not be representative of the entire population of suicide attempters. This is because suicide attempters who use other methods such as burning, hanging, or jumping from heights are referred to other hospitals. However, a systematic review conducted by Quoreishi et al. in the field of suicide attempts showed that the most common plan for suicide was drug overdose (34). Nevertheless, we should still be cautious in generalizing the results of our study to all suicide attempters.

There were some limitations to identifying individuals with ADHD, since retrospective diagnosis of childhood ADHD is associated with a recall bias that is specifically highlighted at the time of the suicide. The accuracy of the study was improved if the interview was conducted by an informed third person, such as a parent or a teacher. Also, the differentiation of ADHD from bipolar disorder or borderline personality disorder was difficult, but ADHD has presented co-morbidity with these disorders $(35,36)$.

\subsection{Conclusion}

ADHD is a common co-morbidity among suicide attempters. Hence, early diagnosis and treatment with consideration of co-ADHD may reduce suicide risk.

\subsection{Suggestions}

Cohort studies in children and adolescents with ADHD and long-term follow-up to adulthood is recommended.

\subsection{Limitations}

Our study sample may not be representative of the entire population of suicide attempters because suicide attempters who use other methods such as burning, hanging, and jumping from heights are referred to other hospitals. 
Table 4. The Prevalence of Quantitative Characteristics Associated With Suicide Attempts in the Case Group ${ }^{\mathrm{a}}$

\begin{tabular}{lrrr}
\hline Variable & Median & Range & 1 le \\
\hline The frequency of previous suicide attempts & 11 & 1 \\
Interval between suicidal thoughts and attempts (months) & $3-60$ & 12 \\
\hline
\end{tabular}

${ }^{\mathrm{a}}$ In both case and control group , the prevalence of ADHD wasn't significant $(\mathrm{P}<0.01)$. The prevalence of adult ADHD in case group $18 \%$, control group 2.9\% , childhood ADHD in case group $35.2 \%$ and control group were $7.7 \%$.

Table 5. A comparison of The Prevalence of ADHD in the Case and Control Groups Based on the Questionnaires (Children or Adult ADHD)

\begin{tabular}{|c|c|c|c|c|c|c|}
\hline Diagnosis & $\mathbf{N}$ & Case Group, No (\%) & Control Group, No. (\%) & OR & CI & P Value \\
\hline Children ADHD & 198 & $166(35.2)$ & $32(7.7)$ & 6.5 & $4.3-9.7$ & $<0.01$ \\
\hline Adult ADHD & 97 & $85(18)$ & $12(2.9)$ & 7.1 & $3.8-13.2$ & $<0.01$ \\
\hline
\end{tabular}

\section{Acknowledgments}

The authors thank all participants in this study.

\section{Footnote}

Authors' Contribution: All authors participated in all stages of preparation of the manuscript. Reza Bidaki and Seyed Ali Mostafavi revised and submitted it.

\section{References}

1. Adler LA, Newcorn JH. The impact, identification, and management of attention-deficit/hyperactivity disorder in adults. Introduction. CNS Spectr. 2007;12(12 Suppl 23):1-2. [PubMed: 18163042].

2. Simon V, Czobor P, Balint S, Meszaros A, Bitter I. Prevalence and correlates of adult attention-deficit hyperactivity disorder: meta-analysis. Br J Psychiatry. 2009;194(3):204-11. doi: 10.1192/bjp.bp.107.048827. [PubMed: 19252145].

3. Mohammadi MR, Mostafavi SA, Keshavarz SA, Eshraghian MR, Hosseinzadeh P, Hosseinzadeh-Attar MJ, et al. Melatonin effects in methylphenidate treated children with attention deficit hyperactivity disorder: a randomized double blind clinical trial. Iran J Psychiatry. 2012;7(2):87-92. [PubMed: 22952551]

4. Adler LA. Clinical presentations of adult patients with ADHD.JClin Psychiatry. 2004;65 Suppl 3:8-11. [PubMed: 15046529].

5. Polderman TJ, Boomsma DI, Bartels M, Verhulst FC, Huizink AC. A systematic review of prospective studies on attention problems and academic achievement. Acta Psychiatr Scand. 2010;122(4):271-84. doi: 10.1111/j.1600-0447.2010.01568.x. [PubMed: 20491715].

6. Mostafavi SA, Mohammadi MR, Hosseinzadeh P, Eshraghian MR, Akhondzadeh S, Hosseinzadeh-Attar MJ, et al. Dietary intake, growth and development of children with ADHD in a randomized clinical trial of Ritalin and Melatonin co-administration: Through circadian cycle modification or appetite enhancement?. Iran J Psychiatry. 2012;7(3):114-9. [PubMed: 23139692].

7. Ingram S, Hechtman L, Morgenstern G. Outcome issues in ADHD: Adolescent and adult long-term outcome. Ment Retard Dev Disabil Res Rev. 1999;5(3):243-50.

8. Barkley RA, Fischer M, Smallish L, Fletcher K. The persistence of attention-deficit/hyperactivity disorder into young adulthood as a function of reporting source and definition of disorder.J Abnorm Psychol. 2002;111(2):279-89. [PubMed: 12003449].
9. Biederman J, Faraone SV, Spencer T, Wilens T, Norman D, Lapey KA, et al. Patterns of psychiatric comorbidity, cognition, and psychosocial functioning in adults with attention deficit hyperactivity disorder. Am J Psychiatry. 1993;150(12):1792-8. doi: 10.1176/ajp.150.12.1792. [PubMed: 8238632].

10. Kooij JJ, Buitelaar JK, van den Oord EJ, Furer JW, Rijnders CA, Hodiamont PP. Internal and external validity of attention-deficit hyperactivity disorder in a population-based sample of adults. Psychol Med. 2005;35(6):817-27. [PubMed: 15997602].

11. Kessler RC, Adler L, Ames M, Barkley RA, Birnbaum H, Greenberg P, et al. The prevalence and effects of adult attention deficit/hyperactivity disorder on work performance in a nationally representative sample of workers. J Occup Environ Med. 2005;47(6):565-72. [PubMed: 15951716].

12. Babinski LM, Hartsough CS, Lambert NM. Childhood conduct problems, hyperactivity-impulsivity, and inattention as predictors of adult criminal activity. J Child Psychol Psychiatry. 1999;40(3):347-55. [PubMed: 10190336].

13. Mannuzza S, Klein RG, Bessler A, Malloy P, LaPadula M. Adult outcome of hyperactive boys. Educational achievement, occupational rank, and psychiatric status. Arch Gen Psychiatry. 1993;50(7):565-76. [PubMed: 8317950].

14. Biederman J, Faraone SV, Spencer TJ, Mick E, Monuteaux MC, Aleardi M. Functional impairments in adults with self-reports of diagnosed ADHD: A controlled study of 1001 adults in the community. J Clin Psychiatry. 2006;67(4):1478-540.

15. Wilens TE, Faraone SV, Biederman J. Attention-deficit/hyperactivity disorder in adults. JAMA. 2004;292(5):619-23. doi: 10.1001/jama.292.5.619. [PubMed: 15292088].

16. Impey $M$, Heun R. Completed suicide, ideation and attempt in attention deficit hyperactivity disorder. Acta Psychiatr Scand. 2012;125(2):93-102. doi: 10.1111/j.1600-0447.2011.01798.x. [PubMed: 22118301].

17. Hajebi A, Ahmadzad-Asl M, Ershadi M, Nikfarjam A, Davoudi F. National registration system of suicide behaviors in Iran: barriers and challenges. Arch Suicide Res. 2013;17(4):416-25. doi: 10.1080/13811118.2013.803445. [PubMed: 24224674].

18. Weiss M, Murray C. Assessment and management of attention-deficit hyperactivity disorder in adults. CMAJ. 2003;168(6):715-22. [PubMed: 12642429].

19. Conners CK, Erhardt D, Sparrow EP. Conners' adult ADHD rating scales (CAARS): technical manual. NewYork: Multi-Health System Inc.; 1999. 
20. Adler LA, Faraone SV, Spencer TJ, Michelson D, Reimherr FW, Glatt SJ, et al. The reliability and validity of self- and investigator ratings of ADHD in adults. J Atten Disord. 2008;11(6):711-9. doi: 10.1177/1087054707308503. [PubMed: 18025250].

21. Davari-Ashtiani R, Arabgol F, Razjouyan K, Khademi M, Jazayeri F. Evaluation of the Validity and Reliability of Adult ADHD Rating Scales (Conners')-Persian version [in Persian]. Iran J Psychiatry. 2012;4(4).

22. Ward MF, Wender PH, Reimherr FW. The Wender Utah Rating Scale: an aid in the retrospective diagnosis of childhood attention deficit hyperactivity disorder. Am J Psychiatry. 1993;150(6):885-90. doi: 10.1176/ajp.150.6.885. [PubMed: 8494063].

23. Rossini ED, O'Connor MA. Retrospective self-reported symptoms of attention-deficit hyperactivity disorder: reliability of the Wender Utah Rating Scale. Psychol Rep. 1995;77(3 Pt 1):751-4. doi: 10.2466/pro.1995.77.3.751. [PubMed: 8559912].

24. Sarrami-Foroushani P. Normalizing and evaluatingthe validity and reliability of the Wender Utah Rating Scale to diagnose ADHD in adults in Isfahan.1999-2000 [Dissertation in Persian]. Isfahan, Iran: Isfahan University of Medical Sciences; 2008.

25. Bayrami M, Goradel JA, Hashemi T, Mahmood MA. Predicting a tendency to use drugs from child and adult attention deficit hyperactivity disorder symptoms in adults. Int J High Risk Behav Addict. 2012;1(3):104-8.

26. Lam LT. Attention deficit disorder and hospitalization due to injury among older adolescents in New South Wales, Australia.JAtten Disord. 2002;6(2):77-82.

27. Kelly TM, Cornelius JR, Clark DB. Psychiatric disorders and attempted suicide among adolescents with substance use disorders. Drug Alcohol Depend. 2004;73(1):87-97. [PubMed:14687963].

28. James A, Lai FH, Dahl C. Attention deficit hyperactivity disorder and suicide: a review of possible associations. Acta Psychiatr Scand. 2004;110(6):408-15. doi: 10.1111/j.1600-0447.2004.00384.x. [PubMed:
15521824].

29. Cho SC, Kim JW, Choi HJ, Kim BN, Shin MS, Lee JH, et al. Associations between symptoms of attention deficit hyperactivity disorder, depression, and suicide in Korean female adolescents. Depress Anxiety. 2008;25(11):E142-6. doi: 10.1002/da.20399. [PubMed: 17937382].

30. Biederman J, Faraone SV, Keenan K, Benjamin J, Krifcher B, Moore C, et al. Further evidence for family-genetic risk factors in attention deficit hyperactivity disorder. Patterns of comorbidity in probands and relatives psychiatrically and pediatrically referred samples. Arch Gen Psychiatry. 1992;49(9):728-38. [PubMed: 1514878].

31. Jamison KR. Suicide and bipolar disorder. J Clin Psychiatry. 2000;61 Suppl 9:47-51. [PubMed: 10826661].

32. Agosti V, Chen Y, Levin FR. Does Attention Deficit Hyperactivity Disorder increase the risk of suicide attempts?. I Affect Disord. 2011;133(3):595-9. doi: 10.1016/j.jad.2011.05.008. [PubMed: 21658780].

33. Goksoyr PK, Nottestad JA. The burden of untreated ADHD among adults: the role of stimulant medication. Addict Behav. 2008;33(2):342-6. doi: 10.1016/j.addbeh.2007.09.008. [PubMed: 17920777].

34. Quoreishi SA. A systematic review of suicide in Iran [in Persian]. Iran J Psychol Psychiatry. 2008;4(2):115-21.

35. Nierenberg AA, Miyahara S, Spencer T, Wisniewski SR, Otto MW, Simon $\mathrm{N}$, et al. Clinical and diagnostic implications of lifetime attentiondeficit/hyperactivity disorder comorbidity in adults with bipolar disorder: data from the first 1000 STEP-BD participants. Biol Psychiatry. 2005;57(11):1467-73. doi:10.1016/j.biopsych.2005.01.036. [PubMed: 15950022].

36. Philipsen A. Differential diagnosis and comorbidity of attentiondeficit/hyperactivity disorder (ADHD) and borderline personality disorder (BPD) in adults. Eur Arch Psychiatry Clin Neurosci. 2006;256 Suppl 1:i42-6. doi: 10.1007/s00406-006-1006-2. [PubMed: 16977551]. 